\title{
Antimicrobial and Antioxidant activity of Echinops emiliae (Asteraceae)
}

\author{
Handan ŞAPCI ${ }^{* 1}$, Cem VURAL ${ }^{2}$, Servet ÖZCAN ${ }^{2}$ \\ ${ }^{1}$ Çukurova University, Vocational School of Aladağ, Forestry Department, Adana, Turkey \\ ${ }^{2}$ Erciyes University, Faculty of Science, Department of Biology, Kayseri, Turkey
}

Received: 02 May 2017 - Accepted: 08 July 2017

\begin{abstract}
The aim of this study was to investigate the antimicrobial and antioxidant activities of different extracts from Echinops emiliae Schwarz ex P. H. Davis. Antimicrobial activity was estimated against several common human pathogenic bacterial strains using the agar disc diffusion and minimal inhibitory concentration assays. Antioxidant activity was evaluated using the total flavanoid and total phenolic content methods. On the light of these experiments, E. emiliae would seem to be an important natural antioxidant. Antimicrobial and antioxidant of $E$. emiliae have not been reported up to now. The results of this study obviously reported that the antimicrobial and antifungal activity could be change with used extracts. Also, the micro dilution method was more sensitive than disk diffusion. This study is first report on the biological activity of E. emiliae as regarded endemic species from Turkey. The results show that E. emiliae could use in the treatment of some illness.
\end{abstract}

Keywords: Anti-bacterial, antifungal, Composite, phenolic content, plant extracts,

\section{INTRODUCTION}

Plants play a pivotal role in the health care of ancient and modern cultures. Plant based drugs or formulations are used to treat various human diseases because they contain the components of therapeutic value. In addition, plant based cures remain an important source of therapeutic agents because of the availability, relatively cheaper cost and non-toxic nature when compared to modern medicine [1-5].

In order to bring pathogenic organisms under control, the use of numerous aromatic herbal essences with antimicrobial activity has been employed. Disc diffusion and micro dilution methods are commonly applied in antimicrobial activity tests. Antioxidants are used for struggle against oxidative stress and damage which pro-oxidants may cause in foods, environment and organisms. Several antioxidant determining methods have been developed in order to define the usability of plants, the natural antioxidant resources, for this purpose. Total phenolic and flavonoid material determination are amongst the commonly used methods. Phenolic and flavonoid materials compose the most important groups of natural antioxidants and these materials are the basic components of plants [6].

As a result of studies carried out with Echinops from the Asteraceae family up to the present, it has been proven that taxa of the Echinops species are effective against migraine, intestinal worms, hemorrhoid, piles, diarrhea, heartache as well as various infections and it has

\footnotetext{
*Corresponding Author E-mail: hsapci@cu.edu.tr
} 
been concluded that they have a wide usage area as an alternative treatment method [7]. The purpose of the present study was to investigate the antimicrobial and antioxidant activity of $E$. emiliae.

\section{MATERIAL and METHODS}

\subsection{Plant Material and Preparation of Extracts}

Echinops emiliae were collected during the project supported by TUBITAK (106T526). These specimens were deposited in the Herbarium of Erciyes University, Turkey. Fresh plant material was washed with tap water. Then it was air dried and chopped into small parts. The powdered material was extracted with hexane, methanol and chloroform. The extract was concentrated by rotavapor (Heidolph, laborota 4000) at reduced pressure below $50^{\circ} \mathrm{C}$.

\subsection{Microorganisms}

The extracts of E. emiliae were assessed against 14 bacteria and a fungi; Staphylococcus aureus ATCC 25923 (gram-positive), Enterococcus faecalis ATCC 29212 (gram-positive), Pseudomonas fluorescens ATCC 49838 (gram-negative), Staphylococcus epidermidis ATCC 12228 (gram-positive), Micrococcus luteus ATCC 10240 (gram-positive), Listeria monocytogenes ATCC 19115 (gram-positive), Bacillus cereus ATCC 11778 (gram-positive), Klebsiella pneumonia ATCC 13883 (gram-negative), Enterobacter aerogenes ATCC 13048 (gram-negative), Escherichia coli ATCC 25922 (gram-negative), Bacillus subtilis ATCC 6633 (gram-positive), Proteus mirabilis ATCC 25933 (gram-negative), Pseudomonas aeruginosa ATCC 27853 (gram-negative), Corynebacterium renale ATCC 19412 (gram-positive), Candida albicans ATCC 90028. The selected microorganisms were antibiotic resistant or multiresistant human pathogens.

\subsection{Antimicrobial Activity Test}

The agar disc diffusion and minimum inhibitory concentration methods were employed for the determination of antimicrobial activity of E. emiliae. Disc diffusion tests were carried out by method of National Committee for Clinical Laboratory Standards [8]. The dried plant extracts were dissolved in Dimethyl Sulfoxide (DMSO). Pure bacterial strains were suspended in Tryptic Soy Broth (TSB, for bacteria) and Yeast Pepton Dekstroz Broth (YPDB, for fungi). The optical density was adjusted to 0.1 at $570 \mathrm{~nm}$ (Shimadzu UV 1800 spectrophotometer). A suspension of the tested microorganism was spread on the solid media plates. Whatman paper disc $(1 \mathrm{~mm})$ was impregnated with $30 \mu 1$ of the extracts and inoculated discs were placed on the plate. After staying at $4{ }^{\circ} \mathrm{C}$ for $2 \mathrm{~h}$, they were incubated at $37^{\circ} \mathrm{C}$ for $24 \mathrm{~h}$. Pure DMSO was used as negative control and three antibiotics (ampicillin, tetracycline and nystatin) were used as positive control. The diameters of the inhibition zones were measured in millimeters. All the tests were run in duplicated.

A minimum inhibition concentration (MIC) tests were carried out by National Committee for Clinical Laboratory Standards [9]. These tests were performed in sterile 96-well micro plates. E. emiliae extracts were prepared as $1000 \mu \mathrm{g} / \mathrm{ml}$ for each solvent, methanol, chloroform, and hexane then transferred to each micro plate well in order to obtain a twofold serial dilution from 1:2 to 1:64. All tests were carried out in MHB, but except for the yeast (YPDB). Plates aerobically were incubated at $37^{\circ} \mathrm{C}$ for $24-48 \mathrm{~h}$. The bacterial growth was indicated by a white "pellet" on the well bottom.

\subsection{Antioxidant Activity}

Echinops emiliae extracts were evaluated by using total flavonoid and phenolic content assay. The total flavonoid content of crude extract was determined by the aluminium chloride colorimetric method [10]. The total flavonoid content was calculated from a calibration curve. 
Quercetin was used to make the calibration curve. Total phenolic content was estimated by Folin Ciocalteu reagent [11]. A $10 \mathrm{ml}$ reaction mixture containing $0.06 \mathrm{mg} / \mathrm{ml}$ extracts of $E$. emiliae, $0.5 \mathrm{ml}$ Folin Ciocalteu reagent and $0.05 \mathrm{ml} 10 \% \mathrm{Na}_{2} \mathrm{CO}_{3}$ was prepared. The mixture was allowed to stand for $2 \mathrm{~h}$ at room temperature. Thereafter, the absorbance of the mixture was measured at $760 \mathrm{~nm}$. Folin Ciocalteu reagent containing $10 \% \mathrm{Na}_{2} \mathrm{CO}_{3}$ was measured as blank. Gallic acid was used as the standard. Total phenolic content of E. emiliae was calculated in terms of Gallic acid equivalents per gram of the tested extracts.

\section{RESULTS}

The percentage productivity for different extracts of E. emiliae was $15.10 \%, 1.53 \%$ and $1.10 \%$ for methanol, chloroform and hexane, respectively. The antimicrobial activity of $E$. emiliae extracts was estimated in vitro by agar diffusion method and MIC assay. $\mathrm{MeOH}$, hexane and chloroform extracts revealed inhibitory affect against all microorganisms at different concentrations (Table 1). The disc diffusion assay results revealed that hexane extracts of $E$. emiliae showed the highest inhibitory activity against C. renale (Table 1). When compared to MIC results, the methanol extracts showed the highest activity (Table 2). The methanol extract of E. emiliae was found to possess antimicrobial activity against to all strains whereas that hexane and chloroform extraxts of E. emiliae showed weaker activity (Table 2,3).

Table 1. Disc diffision method results of Echinops emiliae

\begin{tabular}{llll}
\hline Strain & Methanol & Chloroform & Hexane \\
\hline C. renale & - & $10.51 \mathrm{~mm}$ & $11.45 \mathrm{~mm}$ \\
\hline
\end{tabular}

Table 2. MIC Assay results of Echinops emiliae (Chloroform extract)

\begin{tabular}{|c|c|c|c|c|c|c|c|c|}
\hline \multicolumn{9}{|l|}{ Chloroform } \\
\hline Strains & A & $\mathrm{B}$ & $\mathrm{C}$ & $\mathrm{D}$ & $\mathrm{E}$ & $\mathrm{F}$ & $\mathrm{G}$ & $\mathrm{H}$ \\
\hline Concentration $(\mathrm{mg} / \mathrm{ml})$ & 71.6 & 35.8 & 17.9 & 8.95 & 4.48 & 2.2 & 1.1 & Positive cont. \\
\hline S. aereus & - & - & - & + & + & + & + & + \\
\hline E. faecalis & - & - & - & + & + & + & + & + \\
\hline P. fluorescens & - & - & - & + & + & + & + & + \\
\hline S. epidermidis & - & - & - & + & + & + & + & + \\
\hline M. luteus & - & - & - & + & + & + & + & + \\
\hline L. monocytogenes & - & - & - & + & + & + & + & + \\
\hline B. cereus & - & - & - & + & + & + & + & + \\
\hline K. pneumonia & - & - & - & + & + & + & + & + \\
\hline E. aerogenes & - & - & - & + & + & + & + & + \\
\hline E. coli & - & - & - & + & + & + & + & + \\
\hline B. subtilis & - & - & - & + & + & + & + & + \\
\hline P. aeruginosa & - & - & - & + & + & + & + & + \\
\hline C. renale & - & - & - & + & + & + & + & + \\
\hline P. mirabilis & - & - & - & + & + & + & + & + \\
\hline C. albicans & - & - & - & + & + & + & + & + \\
\hline
\end{tabular}


Table 3. MIC Assay results of Echinops emiliae (Methanol extract)

\begin{tabular}{lllllllll}
\hline Methanol & & & & & & & & \\
Strains & A & B & C & D & E & F & G & H \\
Concentration (mg/ml) & 100 & 50 & 25 & 12.5 & 6.25 & 3.13 & 1.56 & Positive cont. \\
\hline S. aereus & - & - & - & - & - & - & - & + \\
E. faecalis & - & - & - & - & + & + & + & + \\
P. fluorescens & - & - & - & - & + & + & + & + \\
S. epidermidis & - & - & - & + & + & + & + & + \\
M. luteus & - & - & - & - & + & + & + & + \\
L. monocytogenes & - & - & - & - & + & + & + & + \\
B. cereus & - & - & - & - & - & - & + & + \\
K. pneumonia & - & - & + & + & + & + & + & + \\
E. aerogenes & - & - & - & + & + & + & + & + \\
E. coli & - & - & - & - & + & + & + & + \\
B. subtilis & - & - & - & + & + & + & + & + \\
P. aeruginosa & - & - & - & - & + & + & + & + \\
C. renale & - & - & - & - & - & + & + & + \\
P. mirabilis & - & - & - & + & + & + & + & + \\
C. albicans & - & - & - & + & + & + & + & + \\
\hline
\end{tabular}

Table 4. MIC Assay results of Echinops emiliae (Methanol extract)

\begin{tabular}{lllllllll}
\hline Hexane & & & & & & & & \\
Strains & A & B & C & D & E & F & G & H \\
Concentration (mg/ml) & 50 & 25 & 12.5 & 6.25 & 3.13 & 1.6 & 0.8 & $\begin{array}{l}\text { Positive } \\
\text { cont. }\end{array}$ \\
\hline S. aereus & & & & & & & & + \\
E. faecalis & - & - & - & + & + & + & + & + \\
P. fluorescens & - & - & - & + & + & + & + & + \\
S. epidermidis & - & - & - & + & + & + & + & + \\
M. luteus & - & - & - & + & + & + & + & + \\
L. monocytogenes & - & - & - & + & + & + & + & + \\
B. cereus & - & - & - & + & + & + & + & + \\
K. pneumonia & - & - & + & + & + & + & + & + \\
E. aerogenes & - & & + & + & + & + & + & + \\
E. coli & - & - & + & + & + & + & + & + \\
B. subtilis & - & - & + & + & + & + & + & + \\
P. aeruginosa & - & - & + & + & + & + & + & + \\
C. renale & - & - & + & + & + & + & + & + \\
P. mirabilis & - & - & + & + & + & + & + & + \\
C. albicans & - & - & + & + & + & + & + & + \\
\hline
\end{tabular}

Total flavanoid content was estimated by using aluminium chloride colorimetric method. Flavanoid content of the different fractions of E. emiliae was solvent dependent and expressed as milligrams of Quercetin equivalent. Total flavonoid contents of methanol and chloroform extracts of E. emiliae were $4.30 \pm 0.062$, and $2.14 \pm 0.013 \mathrm{mg}$ Quercetin equivalent/g, respectively (Table 5). The highest concentration of flavonoids was estimated in methanol extract, while hexane extracts were not detected considerably concentration of flavonoid. 
Table 5. Total flavanoids and phenolic content of E. emiliae

\begin{tabular}{llll}
\hline & Methanol $(\mathrm{mg} / \mathrm{gr})$ & Chloroform $(\mathrm{mg} / \mathrm{gr})$ & Hexane $(\mathrm{mg} / \mathrm{gr})$ \\
\hline Total flavanoid content & 4.30 & 2.14 & - \\
Total phenolic content & 23.52 & 1.87 & 29,93 \\
\hline
\end{tabular}

Total phenolic content was estimated by using Folin-Ciocalteu reagent. Phenolic content of the different fractions of E. emiliae was solvent dependent and expressed as milligrams of Gallic acid equivalent (GAE). Total phenolic contents of hexane, methanol and chloroform extracts of E. emiliae were $29.93 \pm 0.062,23.52 \pm 0.025$, and $1.87 \pm 0.013 \mathrm{mg}$ Gallic acid equivalent/g, respectively (Table 5). The highest concentration of phenols was estimated in hexane extract. Methanol and hexane extracts contains considerably smaller concentration of phenols.

\section{DISCUSSION}

In vitro antimicrobial and antioxidant activities of E. emiliae the ethanol, methanol, and hexane extracts have not been reported up to now. There are different results between disk diffusion and minimum inhibitory concentration methods. In this study, the micro dilution method was more sensitive than disk diffusion. In the mentioned Kim and Kim [12] the disk diffusion method has some limitations compared with broth micro dilution. Our research and previous papers concerning the biological activities of Echinops species supposed that genus Echinops has important potential in antioxidant systems.

\section{Acknowledgement}

Samples used this study was collected by TUBITAK (Project no: TBAG 106T526).

\section{Conflict of Interests}

Authors declare that there is no conflict of interests.

\section{REFERENCES}

[1] Haslam, E. (1996). Natural polyphenols (vegetable tannins) as drugs: possible modes of action. Journal of Natural Products, 59, 205-215.

[2] Farr, B.M., Salgado, C.D., Karchmer T.B., \& Sherertz R.J. (2001). Can antibiotic-resistant nosocomial infections be controlled? The Lancet Infectious Diseases, 1, 38-45.

[3] Nguefack, J., Somda, I., Mortensen, C.N., \& Zollo, P.H.A. (2005). Evaluation of five essential oils from aromatic plants of Cameroon for controlling seed-borne bacteria of rice (Oryza sativa L.). Seed Science and Technology, 33, 397-407.

[4] Ali-Shtayeh, M.S., Jamous, R.M., Al-Shafie, J.H., Elgharabah, W.A., Kherfan, F.A., Qarariah, K.H., Khdair, I.S., Soos, I.M., Musleh, A.A., Isa, B.A., Herzallah, H.M., Khlaif, R.B., Aiash, S.M., Swaiti, G.M., Abuzahra, M.A., Haj-Ali, M.M., Saifi, N.A., Azem, H.K., \& Nasrallah, H.A. (2008). Traditional knowledge of wild edible plants used in Palestine (Northern West Bank): A comparative study. Journal of Ethnobiology and Ethnomedicine. 4139.

[5] Nissen, N., \& Evans, S. (2012). Exploring the practice and use of Western herbal medicine: Perspectives from the social science literature. J. . Herb. Med. 2, 6-15.

[6] Rice-Evans, C.A., Miller, N.J., \& Paganga, G. (1997). Antioxidant properties of phenolic compounds. Trends Plant Sci. 2, 152-159.

[7] Hymete, A., Iversen, T.H., Rohloff, J., Erko, B. (2005). Screening of Echinops ellenbeckii and Echinops longisetus for biological activities and chemical constituents. Phytomedicine. $12,675-679$. 
[8] NCCLS (National Committee for Clinical Laboratory Standards) (1997). Performance Standards for Antimicrobial Disk Susceptibility Tests. Approved Standard, Wayne Pa NCCLS document A7.

[9] NCCLS (National Committee for Clinical Laboratory Standards) (1999). Performance standards for antimicrobial susceptibility testing. 9th information supplement. M100-S9. Wayne, PA. NCCLS document.

[10] Chang, C., Yang M., Wen, H., \& Chern, J. (2002). Estimation of Total Flavonoid Content in Propolis by Two Complementary Colorimetric Methods. Journal of Food and Drug Analysis. 10, 178-180.

[11] Gamez-Meza, N., Noriega-Rodriguez, J.A., Medina-Juarez, L.A., Ortega-Garcia, J., Cazarez-Casanova, R., \& Angulo-Guerrero O. (1999). Antioxidant Activity in Soybean Oil of Extracts from Thompson Grape Bagasse. Journal of American Oil Chemists' Society. 76, 1445-1447.

[12] Kim, J.S., \& Kim, Y. (2007). The inhibitory effect of natural bioactives on the growth of pathogenic bacteria. Nutrition Research and Practice. 1, 273-278. 